\title{
Designing a breast abscess pathway: a guide for general surgeons
}

This article was published in the following Dove Press journal:

Clinical Audit

\author{
Salma Naseem' \\ Ahmed Hamad ${ }^{2}$ \\ 'Breast Unit, Department of Surgery, \\ Surrey \& Sussex Healthcare NHS \\ Trust, Redhill, UK; ${ }^{2}$ Breast Unit, \\ Department of Surgery, Mid Cheshire \\ NHS Foundation Trust, Crewe, UK
}

\begin{abstract}
Breast infections constitute one of the most common emergencies presenting to the accident and emergency globally with the condition ranging from mild infection to sepsis. These patients are managed by the accident and emergency staff and the on-call general surgeons. Management is variable depending on the expertise of the staff attending to this group. This may lead to unnecessary hospital admission, perhaps culminating in patient dissatisfaction and injudicious use of resources. Herein, based on a single-center study, we propose a simple, clear and pragmatic pathway for acute breast infections. The pathway addresses complete evaluation and states both the indications for conservative and open surgical management. It is hoped that this would achieve an improved patient experience leading to service improvement by eliminating variability of care.
\end{abstract} Keywords: mastitis, breast abscess, antibiotics, breast imaging

\section{Introduction}

Patients presenting with breast symptoms to the accident and emergency (A\&E) department as well as via their general practitioners are managed by the A\&E doctors and the general surgical team on call. The common presentations include infection, abscess and postoperative complications, the majority comprising of "painful red swelling" mastitis or (abscess). Patients are managed in a variable manner that poses health inequality. These patients are initially managed by the general surgical team on call. Often the general surgeons are at a loss as to how best to manage them. Patients may be injudiciously admitted to the hospital when there is already a strain on the bed numbers. There is also no consistency in the regime and the duration of antibiotics prescribed to these patients.

This study is based on an audit conducted at the Mid Cheshire NHS Foundation Trust. The general surgeons and the surgical management raised the identified lack of clarity in the management of such patients. This issue was discussed in the monthly departmental meeting. It was suggested that an evaluation of services should be undertaken to examine the number of patients attending the A\&E department with such symptoms and the treatment offered. During discussion a fair amount of variability in the management of such patients came to our attention.

It was therefore proposed that a streamlined pathway should be designed with a view to incorporating the Trust's policy for antibiotics. This would not only serve as guidelines for the general surgeons but also better management would result in an improved patient experience.
Correspondence: Salma Naseem Surrey \& Sussex Healthcare NHS Trust, Redhill, TNI2EG, UK

Tel +447950952702

Email salma 3 naseem@gmail.com 
This view is reinforced by a Department of Health report titled "An organisation with a memory" which highlights that although the majority of National Health Service (NHS) care is of a high standard and serious errors rarely occur, lessons should be learnt from experience. ${ }^{1}$

\section{Methodology}

This is a retrospective audit of patients in the 10 month period from January to October 2016 admitted with breast infections. Symptoms for attendance, duration of stay, time taken for an ultrasound examination, clinical course and follow-up were examined.

This was undertaken with the aim of designing a pathway for improved service in this group of patients.

Those patients presenting with acute breast problems and admitted to the surgical assessment unit (SAU) were included in the study. These patients were identified from the SAU admissions register. The e-discharges were reviewed from Sunquest ICE Desktop program (Sunquest, Tucson, AZ, USA) for admission and discharge date, clinical course during admission, antibiotics at discharge and follow-up arrangement.

Radiological assessment was recorded by picture archiving and communication system (PACS) for the date they underwent initial ultrasound examination and any subsequent radiological follow-up arranged.

Initially 48 entries in the SAU register were identified. However, 17 patients were excluded from the study: seven were unable to be located by e-discharge and 10 were readmissions for non-acute breast concerns.

\section{Results}

This resulted in a total of 31 patients for the audit. Of these, 24 patients presented with symptoms suggesting infection/ abscess, one presented with mastalgia without any obvious history of trauma, one had metastatic breast cancer and presented with hypercalcemia, five cases had non-infected postoperative complications (Figure 1). Of the 24 patients (78\%) admitted with infection: 16 had abscess/cellulitis, four patients had lactational abscess (post-partum), one post-nipple piercing and one patient developed infection following fine needle aspiration cytology (FNAC) and two had an infected sebaceous cyst (Figure 1).

The average age of the patients was 41 years ranging from 20-74 years. The SAU admission time showed that 17 attended between $8 \mathrm{am}$ and $5 \mathrm{pm}$ with the rest (14) presenting out of hours.

Our study illustrates that the majority of attendances fell in to the first three days of the working week. It was

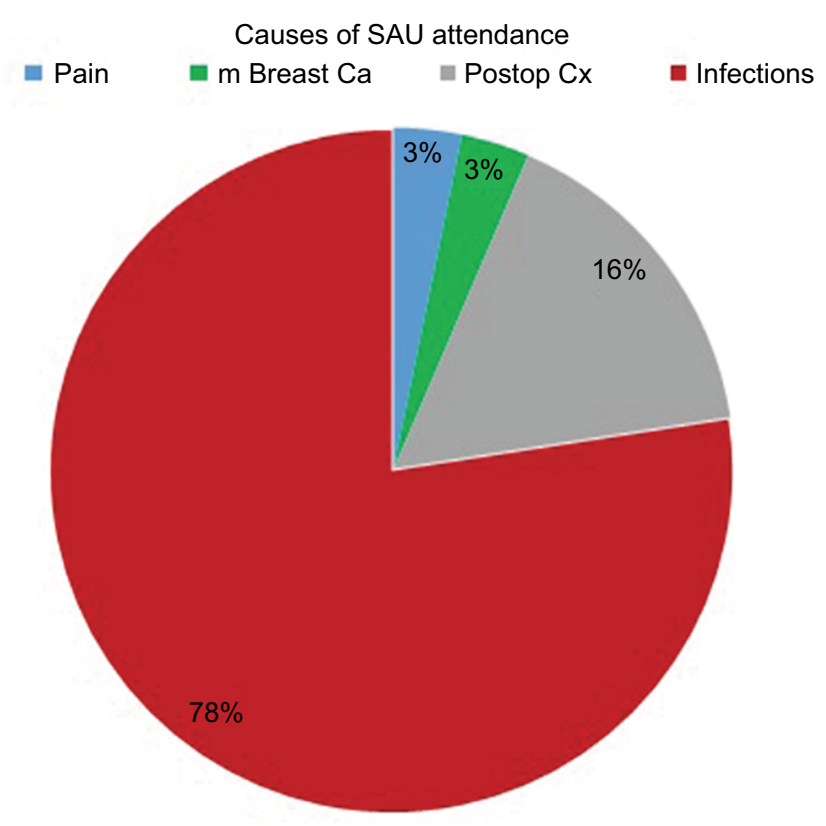

Figure I Reasons for attending SAU.

Abbreviations: $\mathrm{SAU}$, surgical assessment unit; $\mathrm{m}$ Breast $\mathrm{Ca}$, metastatic breast cancer; Postop Cx, postoperative complications.

interesting to note that Friday had the least attendance and that same numbers of patients attended on the weekend, as shown as Figure 2.

A possible explanation of the above may be that the general public perceives Fridays and weekends as the busiest days in NHS hospitals which is often highlighted by the media. In order to avoid long waiting times to be seen, our patients probably chose to wait and attend early the next week.

Figure 3 portrays that 13 out of 31 patients were discharged within $24 \mathrm{~h}$ of admission. However approximately one fifth of the total numbers were inpatients for more than three days.

Out of the total number of admissions to the SAU ( 31 patients), $67 \%$ or 21 patients required ultrasound evaluation.

As Figure 4 shows, the majority of patients 14 out of 21 (67\%) received ultrasound examination 1 day after attendance, one patient underwent ultrasound on the same day, whilst six had to wait $48 \mathrm{~h}$ before they could be evaluated by ultrasound. It is interesting to note that only three patients underwent ultrasound guided aspiration, one patient underwent clinical aspiration.

Ultrasound guided aspiration is recognized as the standard first line of treatment which very few received in our study. We can only assume that this occurred because ultrasound examination facility was not available. Of the remaining 17 patients requiring treatment, three patients were taken to theater for incision and drainage of the abscess. The 


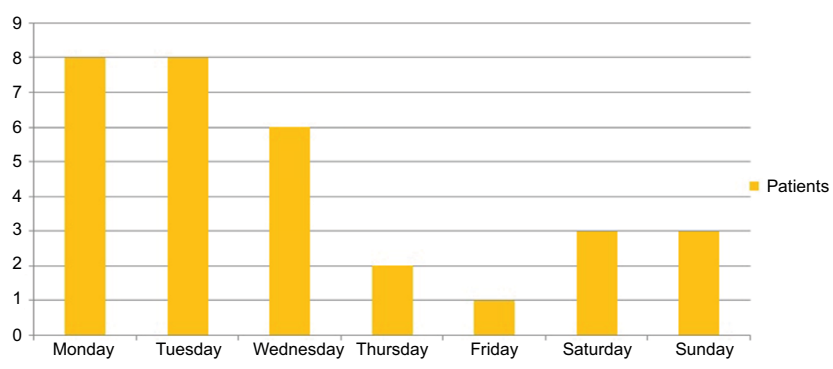

Figure $2 \mathrm{SAU}$ attendance across the week (number of patients). Abbreviation: $\mathrm{SAU}$, surgical assessment unit.

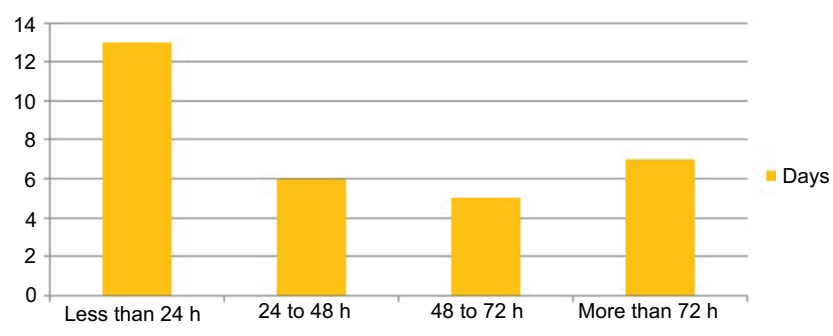

Figure 3 Duration of stay in the SAU (days). Abbreviation: SAU, surgical assessment unit.

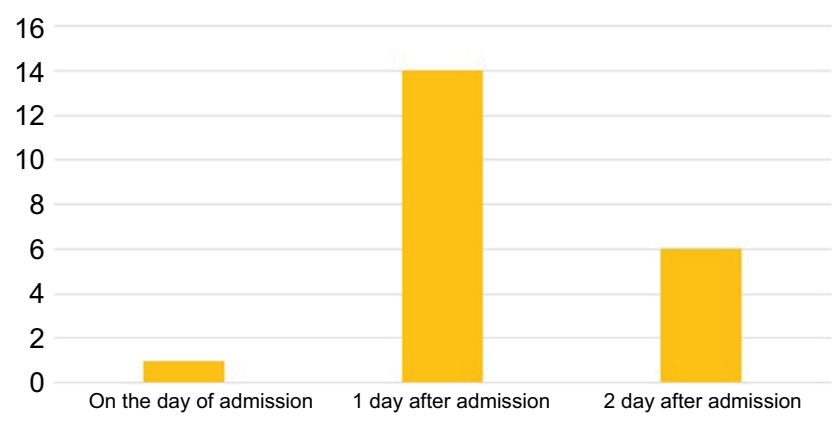

Figure 4 Ultrasound timing in relation to admission (number of patients).

remaining 14 patients did not receive any intervention but were discharged with oral antibiotics.

All patients received antibiotics regardless of the initial management. There was variation in the type of antibiotic prescribed: however the majority received the broad spectrum antibiotic flucloxacillin. The duration of antibiotic usage also varied, ranging from 5-14 days. Follow-up appointment with the breast clinic was organized for all the patients.

\section{Discussion}

Breast infection/abscess is a fairly common surgical emergency presenting in the A\&E department in the UK. It is more common in obese women and in smokers compared to the general population. ${ }^{2}$ This condition can be divided in to lactational, nonlactational and postsurgical. ${ }^{3}$ In addition, the skin overlying the breast can also become infected as a result of infection developing in a pre-existing lesion such as sebaceous cyst or as a generalized skin condition such a hidradenitis suppurativa.

One uncommon presentation that may mimic mastitis is inflammatory breast cancer. The reported incidence is between $2 \%$ and $5 \%$ in the developed world. ${ }^{3}$

Mastitis may be either lactational, nonlactational or postsurgical. Lactational mastitis is most common during the first month or during weaning as the baby's teeth develop. It may culminate in the development of breast abscess. Staphylococcus aureus is the usual organism and it enters the duct system through the nipple. Over half produce penicillinase. ${ }^{4}$ The signs and symptoms of breast abscesses can be either local or systemic. Local symptoms include pain, redness, swelling and tenderness in an area of the breast. As mastitis progresses to an abscess formation a well-defined fluctuant lump may develop in the affected breast. Systemic manifestations include fever, malaise and enlarged axillary lymph nodes.

Nonlactational mastitis can be grouped into peripheral and peri-areolar. The infections in peri-areolar region often present as a mass or an abscess. The organisms are usually mixed and include anaerobes. Peripheral non-lactational breast abscess are more commonly seen in the premenopausal than peri or postmenopausal women. The usual organism being $S$. aureus.

Postsurgical patients may present in the A\&E department in the acute postoperative period or when the wound has healed. The usual practice in breast surgery is to give one single dose of antibiotic whilst the patient is being induced for surgery. ${ }^{5}$ Patients undergoing implant-based surgery or revisional surgery may require prolonged periods of antibiotics. Risk factors and comorbidities should be borne in mind when antibiotic therapy is planned.

An accurate assessment is paramount to institute correct treatment. The clinical problem can be divided in to a cellulitic phase (mastitis) without any pus or an abscess formation. General treatment measures include analgesics, anti-inflammatory medications, breast support and appropriate antibiotics targeting toward antistaphylococcal therapy. Emptying of the breast and breast feeding in a lactating patient should be encouraged. It is difficult to confirm the presence of pus within an inflamed breast clinically therefore ultrasound should be performed for confirmation. ${ }^{6}$ Where possible, ultrasound-guided aspiration is the technique of choice. It provides a simple and effective way for differentiating an abscess from cellulitis and identifying any loculation within the area. ${ }^{7}$ 
If clinically and sonographically pus is confirmed the aim should be aspiration of pus to relieve the symptoms and obtain a sample for microbiological analysis. It is an easy and a relatively simple procedure and can be performed by either the radiologist or the surgeon. Patients should be reviewed every two-to-three days to ensure resolution and reassessment of the condition. Surgical debridement should be reserved for patients presenting with an obvious necrotic overlying skin.

The majority of patients presenting with the above will be either self-referred to the local A\&E department or via their general practitioner. Correct initial assessment is important. Once initial management is instituted patients should be referred to the breast team to ensure appropriate follow-up and advice. This is particularly important in the rare subset of patients with inflammatory breast cancer as the initial

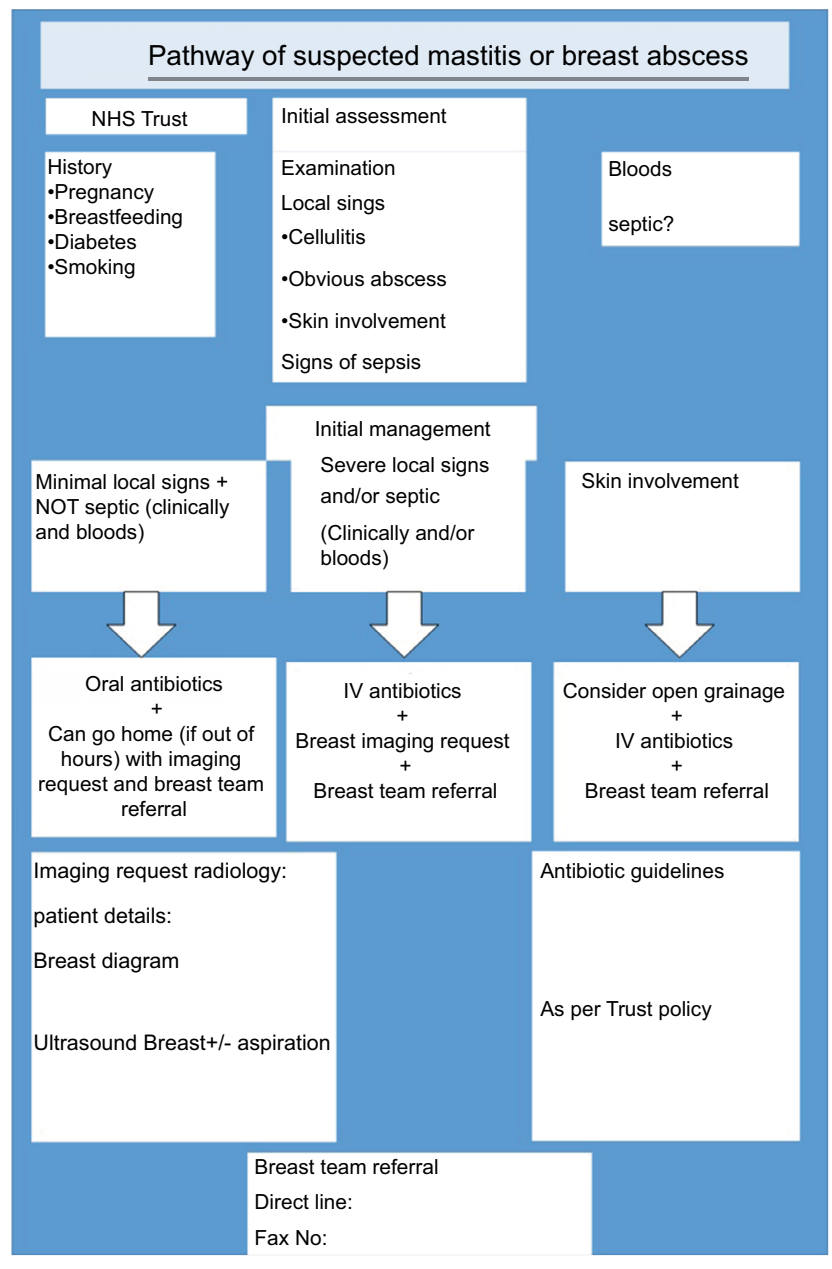

Figure 5 Recommended pathway. Abbreviations: IV, intravenous; NHS, . presentation can be difficult to differentiate. If an inflammatory mass does not respond to the appropriate management, then core biopsy of any abnormal area should be considered.

Whilst the majority of patients are managed on an outpatient basis, note should be made of the number of patients admitted for symptoms suggesting sepsis. This is important as inpatients draw on the resources of the NHS. In the current climate of financial strain it is incumbent on the organization to ensure that resources are allocated judiciously and not wasted.

Our study clearly demonstrates variability in all aspects of management of acute breast problems, thus supporting the concerns of hospital management and the general surgeons on-call. This led to designing a pathway (Figure 5) for a streamlined management of patients presenting with acute breast symptoms. We believe that its simplicity and clarity will not only help general surgeons/A\&E doctors attending to these patients but will also contribute to an improved service. Although our study did not identify any patients with inflammatory breast cancer, doctors should be aware of this condition when managing mastitis.

\section{Ethics approval}

No ethical approval was required for the above study, however it was approved by the local audit committee of the Leighton Hospital.

\section{Disclosure}

The authors report no conflicts of interest in this work.

\section{References}

1. Department of Health. An organisation with a memory. http://webarchive.nationalarchives.gov.uk/20130105144251/http://www.dh.gov. uk/prod_consum_dh/groups/dh_digitalassets/@dh/@en/documents/ digitalasset/dh_4065086.pdf. Accessed September 4, 2018.

2. Schäfer P, Fürrer C, Mermillod B. An association between smoking with recurrent sub-areolar breast abscess. Int J Epidemiol. 1988;17(4):810-813.

3. Sutherland S, Ashley S, Walsh G, et al. Inflammatory breast cancerThe Royal Marsden Hospital experience. Cancer. 2010;116(11 Suppl): 2815-2820.

4. Goodman MA, Benson EA. An evaluation of current trends in the management of breast abscesses. Med J Aust. 1970;1(21):1034-1039.

5. Gupta R, Sinnett D, Carpenter R, Preece PE, Royle GT. Antibiotic prophylaxis for post-operative wound infection in clean elective breast surgery. Eur J Surg Oncol. 2000;26(4):363-366.

6. Hayes R, Michell M, Nunnerley HB. Acute inflammation of the breast the role of breast ultrasound in diagnosis and management. Clin Radiol. 1991;44(4):253-256.

7. Kataria K, Srivastava A, Dhar A. Management of lactational mastitis and breast abscesses: review of current knowledge and practice. Indian J Surg. 2013;75(6):430-435. 
Clinical Audit is an international, peer-reviewed, open access journal focusing on the processes and outcomes of clinical audit in any area of healthcare. All aspects of patient care are addressed within the journal and practitioners from all disciplines are invited to submit their work. Areas covered include: Publication of audits; How an audit has changed practice;

Submit your manuscript here: https://www.dovepress.com/clinical-audit-journal
Dovepress

Practical tips on how to do audits and to avoid pitfalls; How audits have changed patient care; Calls and justifications for new audits. The manuscript management system is completely online and includes a very quick and fair peer-review system, which is all easy to use. Visit http://www.dovepress. com/testimonials.php to read real quotes from published authors. 